\title{
ANÁLISE DAS CORRELAÇÕES ENTRE AS CHUVAS ACUMULADAS E OS DESLIZAMENTOS EM BLUMENAU - SC
}

\author{
Mario Tachini ${ }^{1}$ \\ Dirceu L. Severo² \\ Hélio dos Santos Silva ${ }^{3}$
}

Resumo: A análise das correlações entre as precipitações acumuladas entre um e até sete dias anteriores à ocorrência dos deslizamentos, foi realizada para o período de 2010 e 2017, a partir de três critérios. Os resultados do estudo indicaram que apenas o critério de separação por faixas se mostrou consistente, apresentando uma boa representação da curva de deslizamento relacionada com as chuvas.

Palavras-chave: Chuva. Deslizamentos de Massa. Geologia. Geomorfologia. Blumenau.

\section{ANALYSIS OF CORRELATIONS BETWEEN ACCUMULATED RAINS AND LANDSLIDES IN BLUMENAU - SC}

Abstract: Blumenau (SC) presents a history of social and economic damages associated with floods and landslides. The analysis of the correlations between accumulated rainfall from one and seven days before the occurrence of landslides was performed for the period of 2010 and 2017, based on three criteria. The results of the study indicate that only the point of separation criteria was consistent, presenting a good representation of the rainfall-related landslides curve.

Keywords: Rain. Landslides. Geology. Geomorphology. Blumenau.

\section{ANÁLISIS DE LAS CORRELACIONES ENTRE LAS LLUVAS ACUMULADAS Y LOS DESLIZAMENTOS EN BLUMENAU - SC}

Resumen: Blumenau (SC) presenta un historial de daños sociales y económicos asociados a las inundaciones y deslizamientos de masa. El análisis de las correlaciones entre las precipitaciones acumuladas entre uno y hasta siete días anteriores a la ocurrencia de los deslizamientos, se realizó para el período 2010 y 2017, a partir de tres criterios. Los resultados del estudio indicaron que sólo el criterio de separación por bandas se mostró consistente, presentando una buena representación de la curva de deslizamiento relacionada con las lluvias.

Palabras clave: Lluvia. Deslizamiento de masa. Geología. Geomorfología. Blumenau.

\footnotetext{
1 Universidade Regional de Blumenau, Depto. de Engenharia Civil, Blumenau, mtachini@furb.br, 0000-0003-3616-7542

2 Universidade Regional de Blumenau, Depto. de Física, Blumenau, severo@furb.br, 0000-0001$5701-484 X$

3 Universidade Regional de Blumenau, Depto. de Física, Blumenau, heliosil@furb.br, 0000-00016437-4237
} 


\section{Introdução}

Os deslizamentos são fenômenos naturais do ponto de vista da geociência e influenciados pelas características locais, como: a geologia, geomorfologia, meteorologia e antropogenia. Esses fenômenos podem acontecer em regiões naturais não habitadas, trazendo alterações ambientais. Entretanto, também atingem locais ocupados pela população, que historicamente vêm causando danos cada vez maiores.

As bacias urbanas são as mais delicadas, pois apresentam mais superfícies impermeáveis, maior adensamento das construções e significativa conservação do calor, propiciando a aceleração dos escoamentos e movimentos de massa. Dentro deste contexto, a ocupação dos morros em Blumenau caracteriza uma grande fragilidade socioambiental. Desde o início da colonização a ocupação vem sendo realizada, mas um fator que acelerou a taxa de crescimento nessas áreas foram as grandes enchentes, notadamente as da década de 1980, o que levou a população à procura de lugares mais altos. Além disso, o crescimento da população e a falta de políticas públicas para ocupação do solo urbano levaram a um crescimento desordenado, permitindo que a população ocupasse as regiões mais altas e íngremes da cidade, incluindo áreas de florestas e de preservação.

Este estudo mostra procedimentos de análise do comportamento das chuvas e sua relação aos deslizamentos de solo no município de Blumenau, mostrando os patamares de chuvas potenciais para que ocorra um deslizamento. Assim, é incipiente a aprendizagem do uso das variáveis importantes da hidrologia, como a chuva distribuída ao longo do tempo e do ambiente, tanto da comunidade quanto do poder público. Esta informação pode ser utilizada como um processo norteador dos órgãos públicos e da própria comunidade inserida em áreas de risco.

Ao analisarmos uma chuva e os seus desdobramentos mais trágicos, as inundações e os deslizamentos, podemos enquadrá-los em fenômenos normais quando ficam próximos da média e, eventos extremos, também conhecidos por anomalias. A esse respeito, não existe um consenso absoluto capaz de descrever uma realidade física que desencadeia o fenômeno em si, sem considerar a relação da ação do homem no ambiente e suas consequências. A sociedade não é um receptor passivo do impacto hidrológico e sim, age como um agente potencializador 
de um desastre. Muitas das práticas do crescente progresso das cidades brasileiras estão assentes na subjugação e destruição contínua dos sistemas bióticos e abióticos. Assiste-se a ambientes criados nas cidades, mais susceptíveis aos fenômenos hidrometeorológicos, que revelam ameaças às rotinas dos cidadãos e a sua vulnerabilidade. Os eventos extremos mostram que os esforços de toda a sociedade devem continuar para reduzir a sua vulnerabilidade e melhorar a sua reatividade após os desastres (VALÊNCIO et. al., 2003).

O estudo de correlações entre as chuvas e os deslizamentos é utilizado como critério técnico para a implantação de planos de contingência. A principal aplicação destas correlações é tentar se antecipar à deflagração dos movimentos de massa, a partir do acompanhamento dos índices pluviométricos de uma área, sendo possível alertar antecipadamente as populações do risco de deslizamentos. Desse modo, pode-se afirmar que é mais econômico monitorar o parâmetro chuva do que monitorar o grau de saturação dos taludes e encostas (BRASIL, 2006).

Em um dos trabalhos pioneiros desenvolvido para a região de Cubatão (SP), Tatizana et al. (1987) obtiveram uma curva de correlação entre o acumulado de chuvas de 3,5 dias e deslizamentos (Ministério das Cidades, 2006).

Riekmann et. al. (2005) apresentam um estudo da correlação de chuvas com os deslizamentos, utilizando os dados de chuvas em pluviômetros convencionais, ou seja, com leituras acumuladas em 24 horas para o período de janeiro de 1990 a dezembro de 2003. Os autores, utilizando-se de todos os registros de deslizamentos associados às chuvas acumuladas de 1 a 7 dias, realizaram uma análise das curvas para os casos de (a) baixo valor; (b) médio valor e, (c) valores altos. Os resultados indicaram que os coeficientes de determinação $\left(R^{2}\right)$ foram de $0,80,0,44$ e 0,26, respectivamente. Os mesmos autores sugerem utilizar a curva com os valores médios, haja vista que concentram a maior quantidade de registros de deslizamentos.

Em estudo realizado na cidade Campinas (SP), IDE (2005) sugere que a maior susceptibilidade a escorregamentos ocorre a partir de $70 \mathrm{~mm}$ em 7 dias, para áreas de rochas cristalinas.

Guzzeti et al. (2007) revisaram os limiares pluviométricos para o início de deslizamentos de terra em todo o mundo e propuseram novos limiares de chuva para uma área do centro e sul da Europa. Foram considerados 124 limiares empíricos para as condições de chuva antecedentes à ocorrência de deslizamentos 
de terra. A partir de um banco de dados de 853 eventos pluviométricos que resultaram ou não em deslizamentos de terra foram determinados os valores de duração e intensidade em coordenadas logarítmicas. Os autores observaram que com o aumento da duração das chuvas a intensidade mínima com probabilidade de desencadear um deslizamento diminui linearmente, para um intervalo de durações de 20 minutos a $\sim 12$ dias. As curvas limiares foram inferidas a partir de um modelo bayesiano. A análise dos limiares, permitiu definir que é necessária menor intensidade média de chuvas para iniciar deslizamentos de terra em uma área com clima de montanha, do que em uma área caracterizada por um clima mediterrâneo. Para os autores, os limiares obtidos podem ser usados em sistemas de alerta de deslizamento de terra onde limiares locais ou regionais mais precisos não estão disponíveis.

Molina et. al. (2018) analisaram modelos empíricos para três critérios de chuvas propostas para o município de São Bernardo do Campo (SP), considerando modelos com critério de $50 \mathrm{~mm}$ para 1 dia, $80 \mathrm{~mm}$ para 2 dias, $120 \mathrm{~mm}$ para 3 dias e $150 \mathrm{~mm}$ para 4 dias. Entre os critérios, aquele com maior valor do coeficiente de determinação $\left(R^{2}=0,56\right)$ foi para o último critério. De outro modo, os mesmos autores destacam que uma chuva diária acima de $100 \mathrm{~mm}$ já é suficiente para o desencadeamento de deslizamentos, mesmo que não tenha registro de chuvas em dias anteriores.

Lee et al. (2021) estabeleceram critérios para um sistema de alerta de deslizamento de terra na República da Coreia. Foram derivados limiares ideais para a duração cumulativa das chuvas de eventos e identificadas as características da precipitação associadas a uma alta probabilidade de ocorrência de deslizamento de terra a partir de um modelo bayesiano. O limiar ideal foi determinado comparando os resultados da tabela de contingência e os escores de habilidade que maximizam a probabilidade de detecção e minimizam a probabilidade de detecção falsa. Para o sistema de alerta foram estabelecidos quatro níveis: "normal", "observe", "aviso" e "alerta severo". Os resultados indicaram que o sistema previu um total de $98,2 \%$ das ocorrências de deslizamento de terra nos níveis de "alerta severo" e "alerta". A taxa de alarme falso foi de $0 \%$ para o nível "alerta severo" e 47,4\% para o nível "alerta".

Os eventos de deslizamentos no município de Blumenau são bem documentados na literatura. Em 1990 em um único evento ocorreu a morte de 21 pessoas e no ano de 1997 foram registrados 522 deslizamentos (PMB 2002). No 
período de 1997 a 2001, Vieira (2004) indica que houve 1954 casos de deslizamentos. Ainda Hermann (2001) registra que no período de 1980 a 2000, dentre os municípios pesquisados, Blumenau foi o município que mais registrou casos de deslizamentos.

\section{Metodologia}

O município de Blumenau localiza-se na Zona Fisiográfica do Estado de Santa Catarina designada como "Bacia do rio Itajaí-açu". A cidade situa-se aos $26^{\circ} 55^{\prime} 26^{\prime \prime}$ de Latitude Sul e aos 49 $03^{\prime}$ '22" de Longitude Oeste de Greenwich, distando 89 km em linha reta de Florianópolis, abrangendo uma área de $531 \mathrm{~km}^{2}$ (PMB, 2002). $O$ núcleo urbano encontra-se às margens do rio Itajaí-açu, cortando-o no sentido Oeste - Leste, com largura variável de 200 a 300 metros. Em suas margens predominam morros, desenhando uma faixa estreita e variável, limitando a expansão urbana.

De acordo com Silva et al. (2009), o município de Blumenau apresenta clima subtropical úmido, com períodos de chuvas bem distribuídos. Os períodos mais chuvosos geralmente são registrados nos meses mais quentes, próximos ou durante o verão, com fortes chuvas convectivas, mas comumente frentes frias de passagem pelo sul do país são responsáveis por grandes períodos chuvosos. A Tabela 1 mostra a distribuição mensal da precipitação pluviométrica para a cidade de Blumenau entre os anos de 1981 a 2017. 
Tabela 1 - Distribuição Mensal da precipitação Pluviométrica de Blumenau (SC).

\begin{tabular}{|c|c|c|c|c|c|c|c|c|c|c|c|c|c|}
\hline \multicolumn{14}{|c|}{ DISTRIBUIÇÃO MENSAL DA PRECIPITAÇÃO EM BLUMENAU (1981-2017) } \\
\hline ANOS & JAN & FEV & MAR & ABR & MAI & JUN & JUL & AGO & SET & OUT & NOV & DEZ & TOTAL \\
\hline 1981 & 117,9 & 118,7 & 147,8 & 50,7 & 38,6 & 28,2 & 131,2 & 33,3 & 63,5 & 141,8 & 66,3 & 130,7 & 1068,7 \\
\hline 1982 & 84,5 & 307,0 & 176,3 & 69,4 & 112,5 & 132,1 & 71,1 & 86,3 & 23,1 & 195,4 & 244,4 & 148,7 & 1650,8 \\
\hline 1983 & 272,4 & 154,8 & 190,4 & 115,8 & 263,8 & 168,3 & 542,2 & 82,4 & 207,9 & 91,4 & 138,3 & 307,8 & 2535,5 \\
\hline 1984 & 194,7 & 166,6 & 197,1 & 154,8 & 82,8 & 131,1 & 88,4 & 274,2 & 118,3 & 86,0 & 176,0 & 75,0 & 1745,0 \\
\hline 1985 & 48,1 & 262,9 & 182,2 & 200,5 & 38,0 & 34,2 & 91,8 & 6,7 & 128,0 & 126,3 & 101,8 & 98,2 & 1318,7 \\
\hline 1986 & 157,7 & 230,1 & 67,0 & 162,6 & 82,8 & 29,7 & 48,1 & 87,6 & 124,6 & 142,9 & 107,9 & 220,9 & 1461,9 \\
\hline 1987 & 237,8 & 299,7 & 67,0 & 105,2 & 161,1 & 127,6 & 95,3 & 131,5 & 108,9 & 161,4 & 37,2 & 128,2 & 1660,9 \\
\hline 1988 & 216,4 & 71,9 & 141,9 & 100,0 & 195,2 & 83,1 & 14,3 & 9,4 & 165,4 & 96,3 & 79,2 & 126,0 & 1299,1 \\
\hline 1989 & 578,7 & 154,2 & 177,1 & 97,9 & 94,9 & 46,8 & 109,5 & 61,0 & 172,0 & 91,4 & 64,4 & 173,3 & 1821,2 \\
\hline 1990 & 347,7 & 107,9 & 254,5 & 131,6 & 121,8 & 119,5 & 287,4 & 207,9 & 242,2 & 261,3 & 91,5 & 217,8 & 2391,1 \\
\hline 1991 & 145,6 & 150,6 & 136,4 & 58,6 & 67,7 & 175,6 & 31,4 & 141,9 & 107,7 & 195,7 & 255,1 & 217,9 & 1684,2 \\
\hline 1992 & 320,0 & 232,4 & 150,4 & 75,8 & 430,6 & 154,0 & 146,6 & 125,1 & 91,9 & 45,4 & 141,6 & 53,5 & 1967,3 \\
\hline 1993 & 301,0 & 378,3 & 188,9 & 68,4 & 110,5 & 76,0 & 112,0 & 20,6 & 259,4 & 110,6 & 109,5 & 203,4 & 1938,6 \\
\hline 1994 & 125,1 & 365,0 & 266,0 & 113,0 & 179,6 & 114,2 & 209,9 & 16,6 & 23,8 & 142,3 & 91,7 & 195,3 & 1842,5 \\
\hline 1995 & 454,7 & 213,6 & 84,7 & 42,9 & 4,5 & 131,0 & 131,7 & 50,4 & 193,4 & 110,0 & 60,7 & 75,8 & 1553,4 \\
\hline 1996 & 249,6 & 267,5 & 159,3 & 86,3 & 8,6 & 194,5 & 108,5 & 80,1 & 195,0 & 105,0 & 80,8 & 197,7 & 1732,9 \\
\hline 1997 & 407,5 & 154,6 & 56,4 & 33,5 & 77,8 & 129,6 & 89,1 & 103,8 & 126,2 & 292,3 & 268,4 & 157,5 & 1896,7 \\
\hline 1998 & 386,6 & 207,2 & 284,9 & 197,6 & 30,4 & 70,0 & 155,8 & 264,7 & 326,9 & 160,8 & 66,9 & 181,3 & 2333,1 \\
\hline 1999 & 210,6 & 186,4 & 175,5 & 82,0 & 59,2 & 72,0 & 152,9 & 12,4 & 143,4 & 215,8 & 110,9 & 119,0 & 1540,1 \\
\hline 2000 & 231,4 & 227,8 & 200,6 & 38,2 & 42,8 & 93,1 & 43,9 & 68,4 & 184,5 & 128,6 & 72,6 & 218,7 & 1550,6 \\
\hline 2001 & 235,7 & 193,4 & 204,8 & 139,5 & 155,8 & 91,4 & 98,3 & 72,0 & 248,2 & 75,7 & 102,2 & 122,8 & 1739,8 \\
\hline 2002 & 126,3 & 89,2 & 86,4 & 133,3 & 37,4 & 48,7 & 74,1 & 84,3 & 165,6 & 132,4 & 124,5 & 165,3 & 1267,5 \\
\hline 2003 & 70,6 & 71,5 & 317,6 & 42,6 & 29,3 & 112,7 & 57,1 & 9,4 & 96,5 & 124,5 & 58,7 & 201,8 & 1192,3 \\
\hline 2004 & 167,2 & 159,9 & 127,3 & 65,5 & 112,0 & 80,3 & 193,2 & 58,3 & 145,9 & 220,7 & 101,7 & 137,7 & 1569,7 \\
\hline 2005 & 220,8 & 65,4 & 60,7 & 175,5 & 183,5 & 90,3 & 100,4 & 192,7 & 242,0 & 171,0 & 92,9 & 121,9 & 1717,1 \\
\hline 2006 & 135,6 & 82,5 & 91,5 & 18,3 & 26,3 & 31,6 & 57,5 & 74,6 & 71,4 & 80,0 & 165,0 & 136,6 & 970,9 \\
\hline 2007 & 180,3 & 214,4 & 91,9 & 68,8 & 207,1 & 28,3 & 126,8 & 104,6 & 61,7 & 132,7 & 141,3 & 206,6 & 1564,5 \\
\hline 2008 & 273,1 & 155,3 & 58,5 & 184,8 & 60,1 & 79,1 & 30,6 & 102,9 & 147,0 & 360,1 & 1001,2 & 166,4 & 2619,1 \\
\hline 2009 & 281,7 & 198,5 & 78,5 & 49,1 & 62,4 & 39,3 & 272,1 & 123,1 & 296,4 & 145,1 & 246,5 & 96,0 & 1888,7 \\
\hline 2010 & 378,4 & 126,9 & 182,2 & 227,2 & 180,4 & 149,8 & 149,7 & 54,9 & 80,1 & 147,3 & 135,4 & 270,0 & 2082,3 \\
\hline 2011 & 422,6 & 249,4 & 299,3 & 117,8 & 97,9 & 121,1 & 211,5 & 333,5 & 248,7 & 132,7 & 49,1 & 182,0 & 2465,6 \\
\hline 2012 & 334,8 & 137,7 & 135,1 & 159,5 & 126,3 & 161,3 & 213,0 & 16,9 & 65,9 & 116,7 & 44,6 & 128,5 & 1640,3 \\
\hline 2013 & 82,5 & 152,2 & 133,1 & 126,1 & 118,6 & 216,6 & 157,2 & 138,3 & 233,7 & 123,3 & 96,8 & 119,4 & 1697,8 \\
\hline 2014 & 204,9 & 181,4 & 288,8 & 61,8 & 94,7 & 331,1 & 64,7 & 122,5 & 202,5 & 53,8 & 146,0 & 194,0 & 1946,2 \\
\hline 2015 & 252,3 & 271,0 & 164,7 & 92,2 & 182,3 & 145,0 & 158,4 & 24,4 & 224,3 & 334,9 & 158,0 & 181,3 & 2188,8 \\
\hline 2016 & 122,2 & 194,9 & 239,9 & 94,5 & 95,8 & 72,6 & 66,2 & 179,5 & 57,3 & 205,6 & 121,9 & 231,6 & 1682,0 \\
\hline 2017 & 247,8 & 124,0 & 110,4 & 106,0 & 263,8 & 116,9 & 5,9 & 74,8 & 78,4 & 89,6 & 178,6 & 133,5 & 1529,7 \\
\hline Média & 238,5 & 187,2 & 161,5 & 104,0 & 114,5 & 108,8 & 127,0 & 98,1 & 153,3 & 149,9 & 144,0 & 163,3 & 1750,1 \\
\hline Máxima & 578,7 & 378,3 & 317,6 & 227,2 & 430,6 & 331,1 & 542,2 & 333,5 & 326,9 & 360,1 & 1001,2 & 307,8 & 2619,1 \\
\hline Mínima & 48,1 & 65,4 & 56,4 & 18,3 & 4,5 & 28,2 & 5,9 & 6,7 & 23,1 & 45,4 & 37,2 & 53,5 & 970,9 \\
\hline
\end{tabular}

Fonte: CEOPS/FURB

A topografia da região urbana do município de Blumenau é bastante acidentada, apresentando grandes diferenças de altitude, variando de 14 a 200 metros. Geologicamente, no município são encontradas quatro unidades estratigráficas: Complexo Granulítico; Complexo Metamórfico Brusque, Grupo Itajaí e dos Sedimentos Quaternários Frequentes. Dessas unidades as que apresentam problemas de deslizamentos mais significativos estão presentes no Complexo 
Metamórfico Brusque e do Grupo Itajaí, inseridas na região dos Bairros Garcia e, Bairros da Velha e Fortaleza, respectivamente (XAVIER, 1996).

Para este estudo foram utilizados dados históricos de precipitação e deslizamentos no período de janeiro de 2010 a março de 2017. As informações de chuva foram obtidas no site da Agência Nacional de Águas (www.ana.org.br), para o posto número 02649006, com chuvas acumuladas até 15 minutos e do Cemaden (www.cemaden.gov.br), para 08 postos pluviométricos automáticos, distribuídos ao longo do município, com chuvas acumuladas até 10 minutos, assim identificados: Centro, Glória, Fortaleza, Itoupava Central, Ponta Aguda, Progresso, Velha Central e Velha Grande. A Figura 1 indica a distribuição dos bairros no território do município.

Figura 1 - O município de Blumenau e distribuição dos bairros.

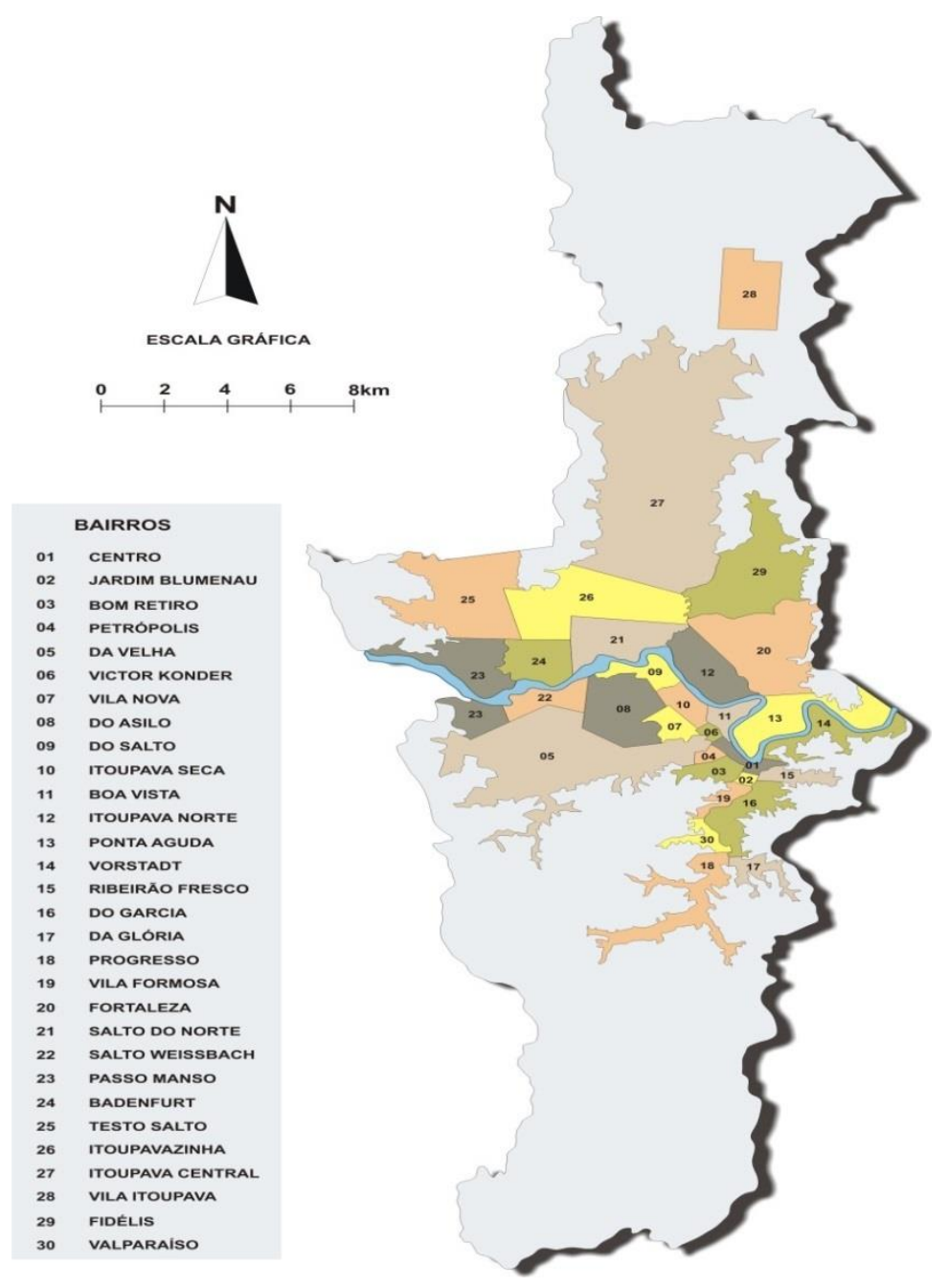

Os registros de deslizamentos, obtidos da Defesa Civil do município, estão identificados por bairros. Desse modo, procurou-se associá-los aos dados de chuva dos bairros correspondentes. Contudo, inúmeras vezes ocorreram falhas desses 
registros temporais, mormente em vários postos telepluviométricos, necessitando agregar dados de postos vizinhos dos registros de deslizamentos. Para preencher a falta de dados em registros de deslizamentos, utilizaram-se os dados do posto da ANA, localizado no centro do município.

As séries de precipitação passaram por várias análises, a partir dos seguintes critérios: (a) acumuladas de chuvas por dia e associadas à maior intensidade para o dia restante, considerando quatro macrorregiões do município (Centro, Norte, Oeste e Sul); (b) acumuladas de chuvas por dia, de todos os registros e associadas para o acumulado do dia restante, porém segregadas pelos critérios de séries abaixo da média, séries dentro da média e, séries acima da média; (c) critério de acumulados de chuvas por dia, de todos os registros 1 a 7 dias e associados ao dia restante, com a segregação por totais até $50 \mathrm{~mm}$, de 51 a $75 \mathrm{~mm}$, de 76 a $100 \mathrm{~mm}$ e eventos extremos acima de $100 \mathrm{~mm}$.

Foram gerados diagramas de dispersão dos dados de chuvas e ajustados pela equação (1):

$$
\text { Pr }=k *(P a c)^{-b}
$$

Onde:

$\operatorname{Pr}=$ precipitação restante;

$P a c=$ precipitação acumulada de 1 a 7 dias;

$k, b=$ constantes de relação geométrica.

Resultados

A partir dos dados de deslizamentos registrados pela SEDECI, apresentados na Tabela 2, verificou-se que os meses de janeiro, fevereiro, março, abril e setembro são responsáveis por $80 \%$ dos deslizamentos no município de Blumenau, para o período compreendido entre 2010 a março de 2017. Somente no ano de 2011 ocorreram $39 \%$ dos registros de deslizamentos, destacando o mês de setembro com $19 \%$ de ocorrências. 
Tabela 2 - Registros mensais de ocorrências de deslizamentos em Blumenau (Período 2010 - 2017)

\begin{tabular}{|c|c|c|c|c|c|c|c|c|c|c|c|c|}
\hline Ano & Janeiro & Fevereiro & Março & Abril & Maio & Junho & Juho & Agosto & Setembro & Outubro & Novembro & Dezembro \\
\hline 2010 & 106 & 25 & 12 & 95 & 13 & 11 & 11 & 10 & 5 & 1 & 2 & 15 \\
\hline 2011 & 129 & 37 & 74 & 16 & 7 & 4 & 8 & 73 & 344 & 11 & 5 & 7 \\
\hline 2012 & 18 & 1 & 3 & 2 & 0 & 4 & 13 & 6 & 1 & 5 & 3 & 3 \\
\hline 2013 & 4 & 3 & 8 & 13 & 6 & 6 & 5 & 10 & 88 & 0 & 1 & 3 \\
\hline 2014 & 5 & 6 & 78 & 0 & 2 & 8 & 0 & 1 & 5 & 0 & 5 & 1 \\
\hline 2015 & 11 & 23 & 4 & 0 & 25 & 16 & 8 & 0 & 5 & 39 & 7 & 0 \\
\hline 2016 & 1 & 25 & 13 & 3 & 2 & 3 & 2 & 9 & 1 & 1 & 1 & 0 \\
\hline 2017 & 202 & 7 & 68 & & & & & & & & & \\
\hline Soma & 476 & 127 & 260 & 129 & 55 & 52 & 47 & 109 & 449 & 57 & 24 & 29 \\
\hline
\end{tabular}

Com a relação dos registros de escorregamentos e o acumulado de chuva de 1 a 7 dias, mais o total de chuva remanescente, procedeu-se a análise dos diagramas, a partir de critérios por dias acumulados para macrorregiões do município, apresentados no item 3.1.

Critério por dias acumulados para macrorregiões do município

Os eventos chuvosos que evidenciaram deslizamentos permitiram serem agrupados em 1 dia, 2 dias, 3 dias, 4 dias, 5 dias e 7 dias. Verificou-se uma dispersão elevada em todos os diagramas, de modo que os coeficientes de correlação entre a curva e os pontos são da ordem de 0,$270 ; 0,286 ; 0,003 ; 0,294$; 0,004 e, 0,118, respectivamente. Com estas correlações, seria praticamente impossível determinar um patamar de chuvas para que ocasione um deslizamento.

Para buscar uma melhoria nos coeficientes de correlação, procurou-se reunir todos os registros em uma única planilha, determinando-se a média e o desvio padrão dos acumulados de 1 a 7 dias.

\section{Critério dos valores médios}

Procurou-se dividir todos os registros de chuvas acumuladas em ordem crescente, em quatro grupos distintos, numa tentativa de uma melhor distribuição dos diferentes patamares, sendo eles: (a) todos os dados reunidos; (b) valores 
mínimos, considerando-os dados menores que a média, menos o desvio padrão; (c) valores médios, considerando os valores médios mais o desvio padrão e, (d) valores extremos, ou seja, acima do critério anterior.

$\mathrm{Na}$ Figura 2 são apresentados todos os registros de deslizamento correlacionados às chuvas acumuladas de 1 a 7 dias. O diagrama de dispersão mostra que o ajuste da curva foi muito fraco, uma vez que o coeficiente de determinação foi muito baixo, ou seja, de 0,18.

Figura 2 - Curva de correlação com todos os valores de chuva acumulada

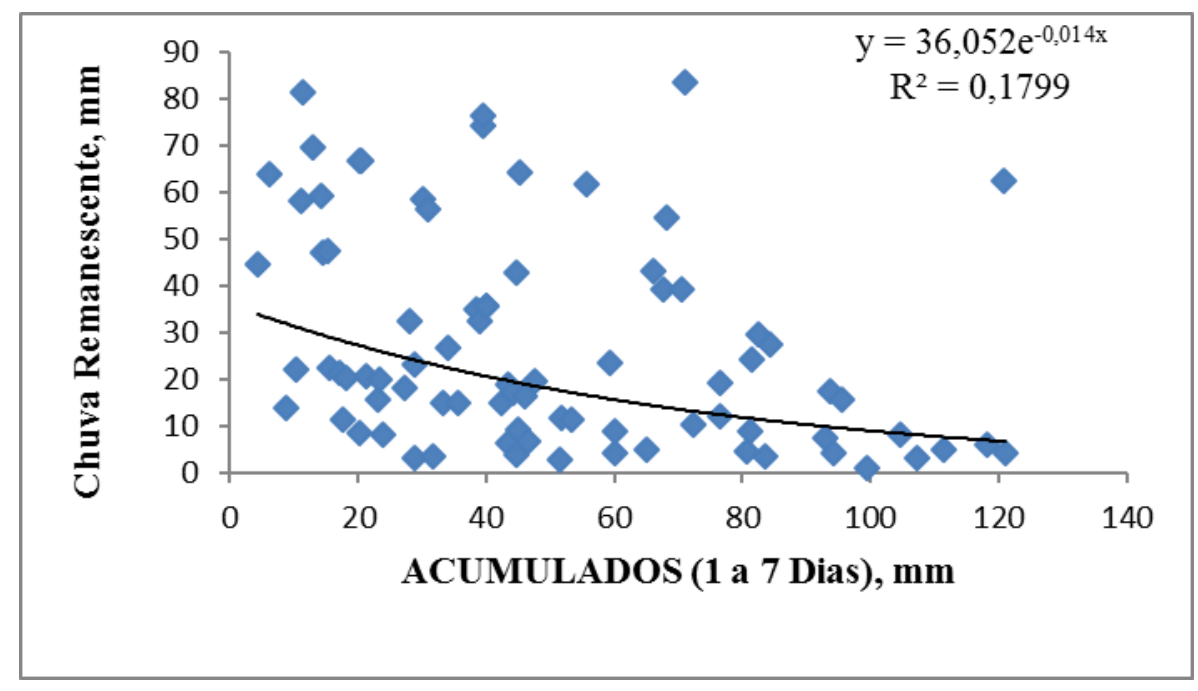

Do mesmo modo, as Figuras 3 a 5 apresentam as distribuições de diferentes patamares e suas respectivas dispersões também muito altas, praticamente impossíveis de determinar um patamar de chuvas para que ocasionem deslizamentos.

Figura 3 - Curva de correlação para valores de chuva acumulada Mínima

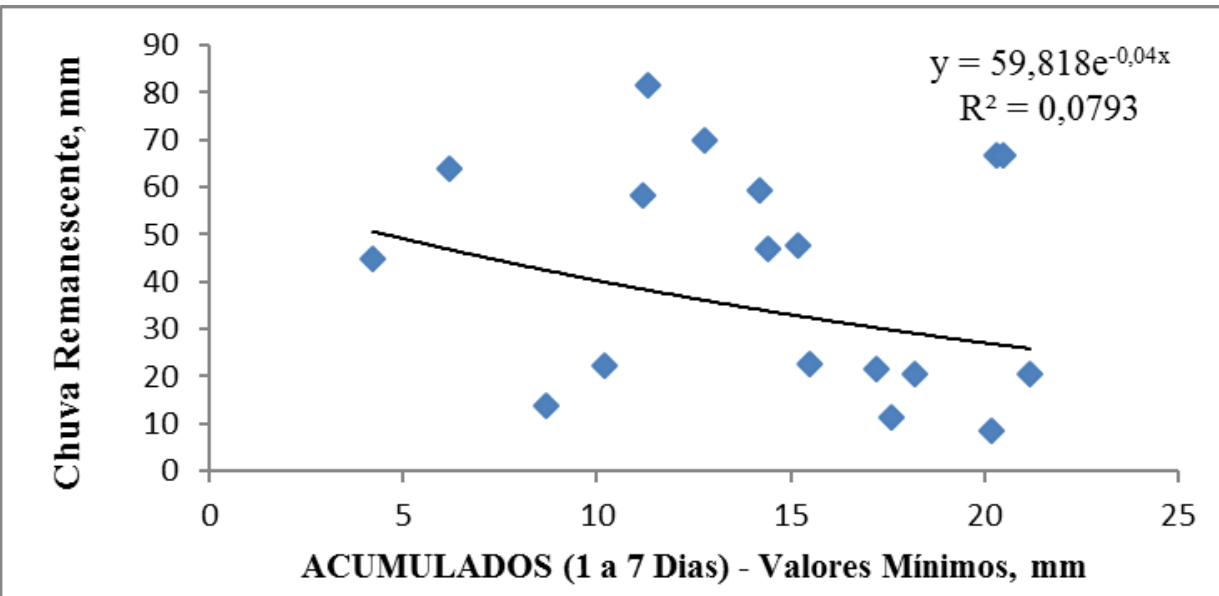


Figura 4 - Curva de correlação para valores de chuva acumulada média

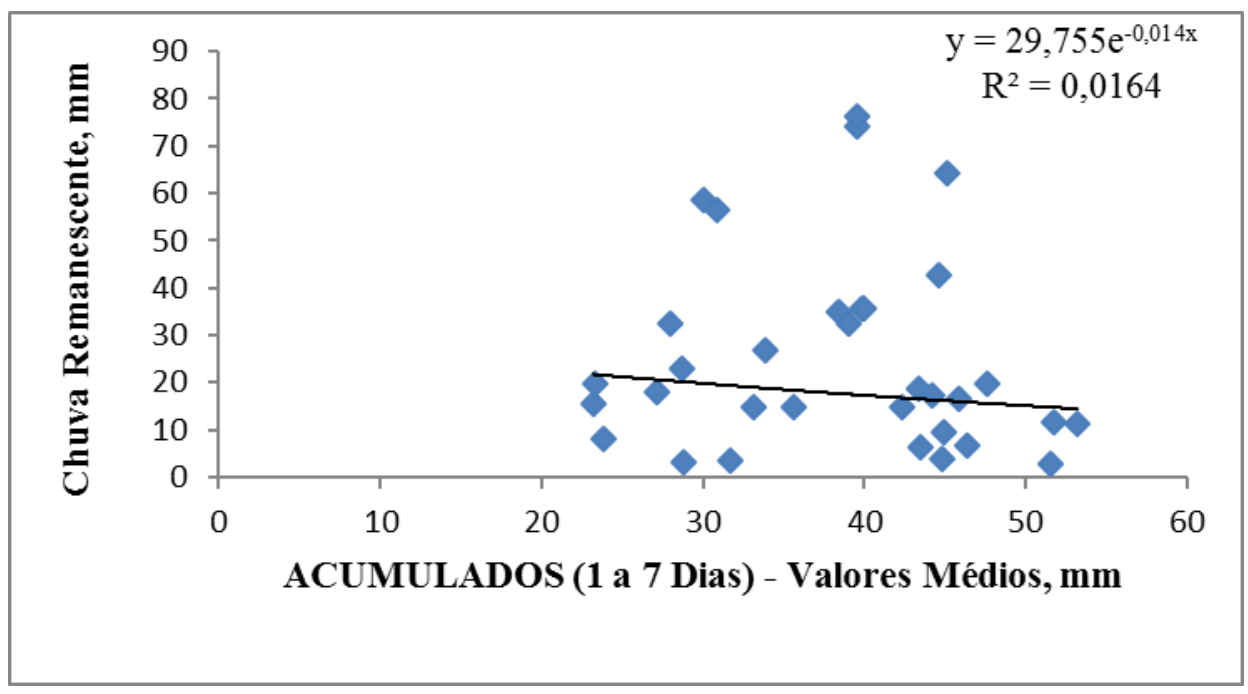

Figura 5 - Curva de correlação para valores de chuva acumulada máxima

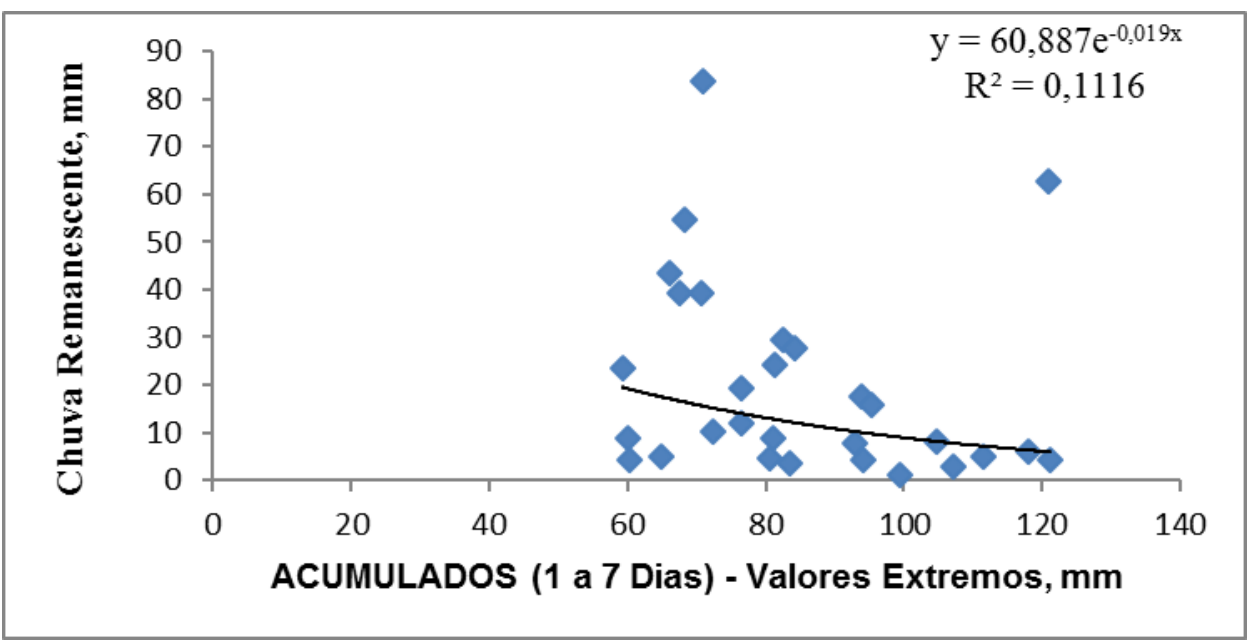

Para uma melhor compreensão do comportamento das chuvas, procurou-se separar os totais acumulados de 1 a 7 dias em quatro faixas: a) até $50 \mathrm{~mm}$; b) de 51 a $75 \mathrm{~mm}$; c) de 76 a $100 \mathrm{~mm}$ e, d) acima de $100 \mathrm{~mm}$. Esse critério é apresentado no item 4.3.

\section{Critério por faixas}

Considerando a série de dados com registros de deslizamentos, associados aos totais de chuva acumulado e, incluindo-se a chuva remanescente, definiu-se quatro critérios de análise. 
Dentre os diagramas gerados aquele que apresentou o menor valor do coeficiente de determinação foi o critério que relaciona os deslizamentos com chuvas até $50 \mathrm{~mm}$, ou seja, $\mathrm{R}^{2}=0,5076$ (Figura 6 ).

Para o segundo critério, considerando chuvas para intervalo de 51 a $75 \mathrm{~mm}$, verificou-se que o valor do coeficiente de determinação foi de 0,8068 , mostrando que a equação ajustada representa muito bem a correlação entre as chuvas e os deslizamentos (Figura 7).

A Figura 8 apresenta o terceiro critério, com a correlação entre as chuvas acumuladas até 76 até $100 \mathrm{~mm}$ e os registros de deslizamentos. Para esta faixa, verificou-se que o valor do coeficiente de determinação foi de 0,8968 , mostrando um ajuste excepcional para a correlação entre as chuvas e os deslizamentos.

Considerando ainda o último critério, a Figura 9 mostra a associação das chuvas acumuladas com valores superiores a $100 \mathrm{~mm}$ e os deslizamentos. Para este caso, o valor do coeficiente de determinação foi de 0,5239 , mostrando que a equação ajustada representa razoavelmente bem a correlação entre as chuvas e os deslizamentos.

Figura 6 - Curva de correlação para chuva acumulada até $50 \mathrm{~mm}$

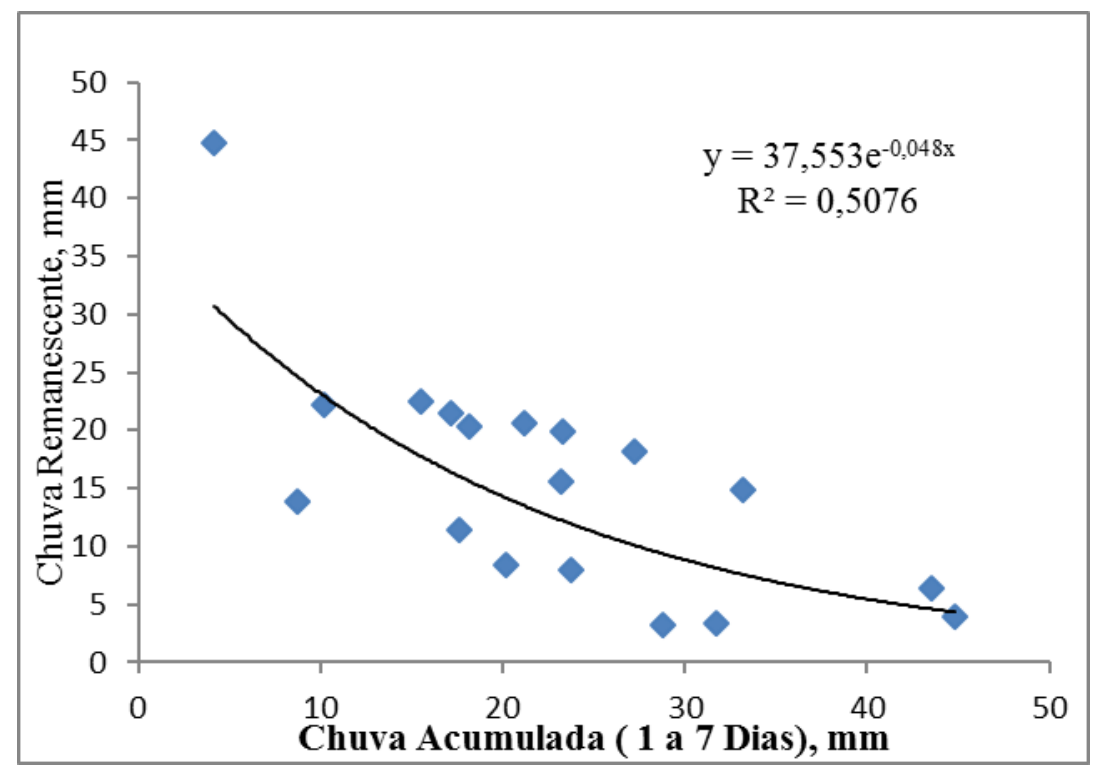


TACHINI, SEVERO, SILVA

Figura 7 - Curva de correlação para chuva acumulada até 51 até $75 \mathrm{~mm}$

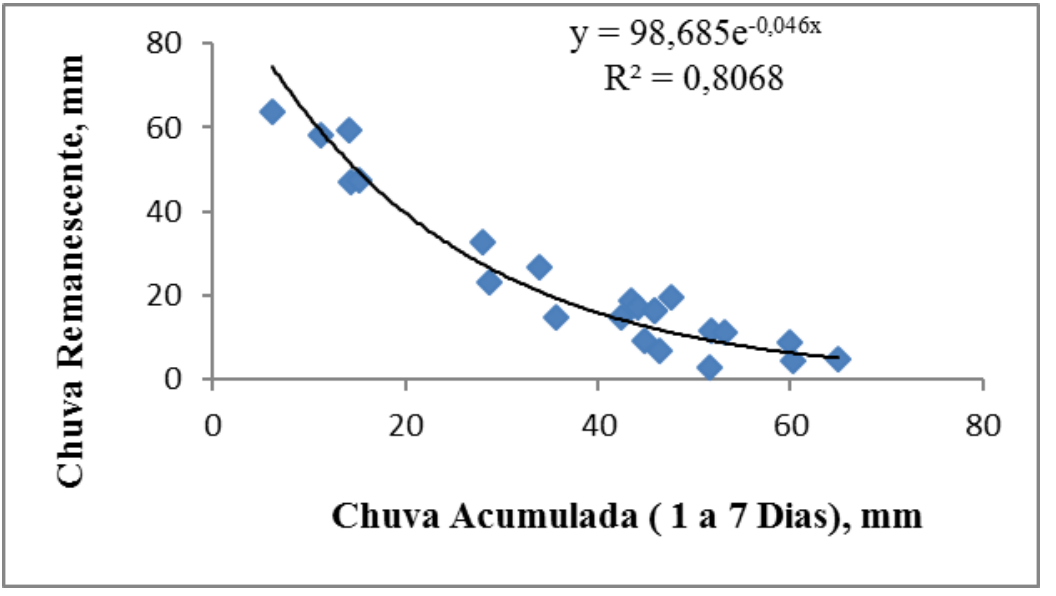

Figura 8 - Curva de correlação para chuva acumulada até 76 até $100 \mathrm{~mm}$

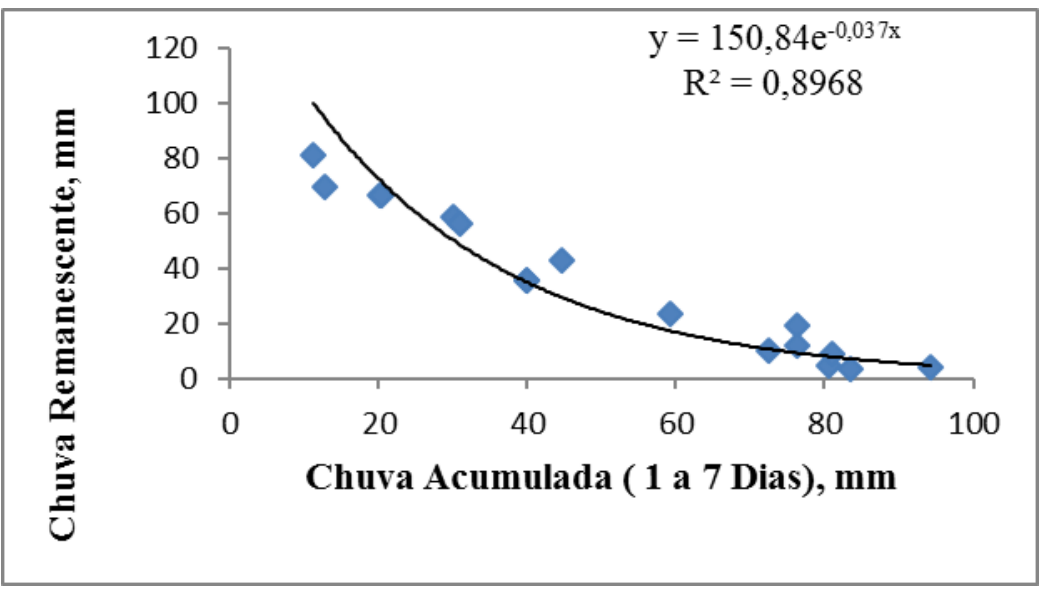

Figura 9 - Curva de correlação para chuva acumulada superior a 100 mm

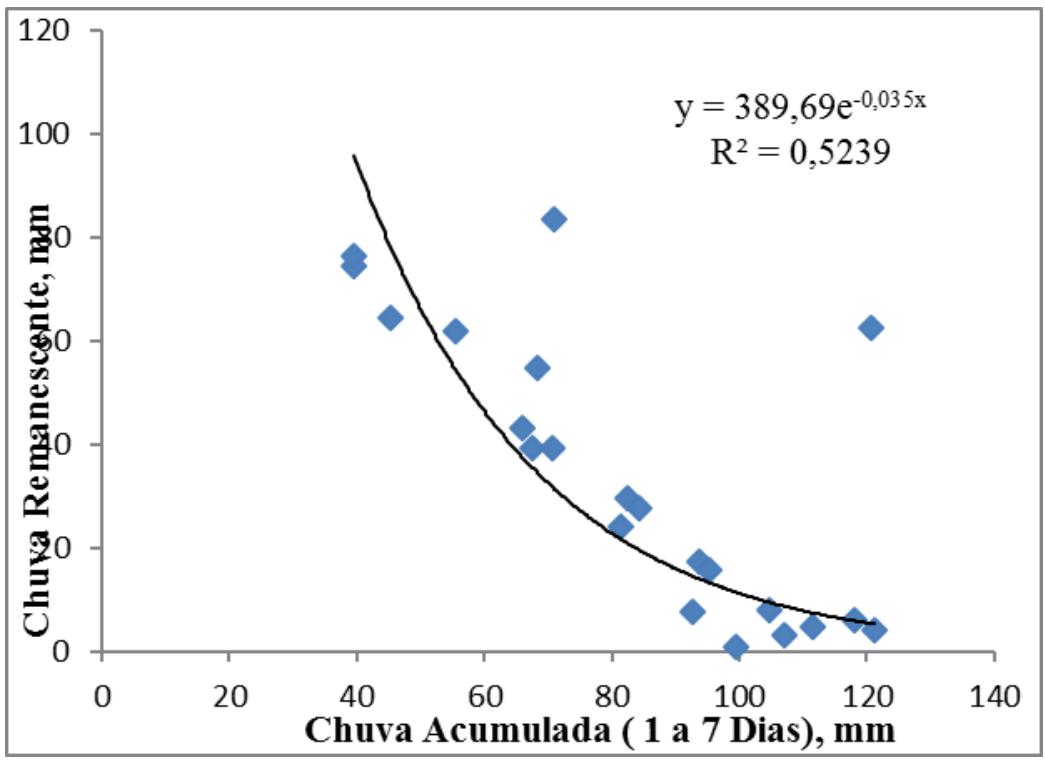




\section{Considerações Finais}

Blumenau apresenta chuvas distribuídas ao longo do ano, com mais frequência nos meses próximos e durante o verão, caracterizadas em muitos eventos, com chuvas diárias próximas ou superiores a $100 \mathrm{~mm}$. Em muitos desses eventos de chuvas intensas ocorrerem diversos deslizamentos.

O estudo analisou três critérios visando definir o melhor ajuste entre as chuvas associadas aos deslizamentos. Observou-se que os melhores ajustes foram obtidos para o modelo definido por faixas de chuvas acumuladas. Destacando as chuvas acumuladas, entre 1 a 7 dias, a partir de 51 até $75 \mathrm{~mm}$ e, de 76 a $100 \mathrm{~mm}$, com os coeficientes de determinação de 0,8068 e 0,8968, respectivamente, indicando uma ótima divisão dos eventos de deslizamentos.

A série analisada de eventos com deslizamentos mostrou que os mesmos podem ocorrer a partir de chuvas intensas em menos de 24 horas e acumuladas até 7 dias. Mostrando, portanto o grau de dificuldades para a definição da curva que represente os valores próximos dos reais de deslizamentos.

\section{REFERÊNCIAS}

BLUMENAU, Prefeitura Municipal De. Plano Diretor de Defesa Civil, 2002. 147p.

BRASIL - Ministério das Cidades / Cities Alliance. Prevenção de riscos de deslizamentos em encostas: Guia para elaboração de políticas municipais / Celso Santos Carvalho e Thiago Galvão (org.). Brasília: Ministério das Cidades; Cities Alliance, 2006, 111 p.

IDE, F.S. Deslizamento, meteorologia e precipitação: uma proposta de método de investigação para prevenção e monitoramento aplicado em Campinas/SP.Dissertação Instituto de Pesquisas Tecnológicas (IPT) do Estado de São Paulo, 2005. Disponível em < https://www.ipt.br/dissertações interna click. Acesso em 08/08/2018.

GUZZETTI, F., PERUCCACCI, S., ROSSI, M. et al 2007: Rainfall thresholds for the initiation of landslides in central and southern Europe. Meteorol. Atmos. Phys. 98, 239-267.

https://doi.org/10.1007/s00703-007-0262-7

HERRMANN, Maria Lúcia de Paula (2001). Levantamento dos desastres naturais causados pelas adversidades climáticas no Estado de Santa Catarina, período 1980 a 2000. Florianópolis: IOESC, 92 p.

LEE, W.Y.; PARK, S.K.; SUNG, H.H. 2021: The optimal rainfall thresholds and probabilistic rainfall conditions for a landslide early warning system for Chuncheon, Republic of Korea.

Landslides. https://doi.org/10.1007/s10346-020-01603-3 
MOLINA, Ellen. NOGUEIRA, Fernando Rocha. Cardoso, Andrea. Relação precipitaçãodeslizamento no município de São Bernardo do Campo - SP. Disponível em < https://www.researchgate.net/publication/277349551. Acesso em 08/08/2018.

RIEKMANN, C. G.; PINHEIRO, A.; TACHINI, M. Estudo da relação entre chuvas e deslizamentos em áreas de risco em Blumenau - SC. ABRH - Sul, Santa Maria - RS, 2005.

SILVA, H.S. e Severo, D.L., O Clima, in Aumond, J.J. et al. (org). Bacia do Itajaí:

Formação, Recursos Naturais e Ecossistemas, Blumenau, Edifurb, 2009 (in press).

TATIZANA, Celso; OGURA, Agostinho Tadashi; CERRI, Lendro E. da Silva; ROCHA, Mirian Cassia Médici da. Escorregamentos - Serra do Mar, Municípios de Cubatão. Anais do 5ํㅜㅇ congresso brasileiro de geologia e engenharia. Instituto de Pesquisas Tecnológicas de São Paulo S.A. - IPT, 1987, 23 p.

VALÊNCIO, N. F. L. S.; CAMPOS, P. F. C.; TRIVELIN, I. M. Gestão de desastres no Brasil: considerações sociais acerca das políticas de emergência ante os perigos

hidrometeorológicos. In: MARTINS, R. C.; VALÊNCIO, N. F. L. S. (Orgs.). Uso e gestão dos recursos hídricos no Brasil: desafios teóricos e políticos-institucionais. São Carlos: RiMa Editora, v. II, 2003, p. 223-237.

XAVIER, Fernando da Fontoura. Caracterização Geotécnica do Município de Blumenau: Dados preliminares. In: CONGRESSO BRASILEIRO DE GEOLOGIA DE ENGENHARIA, 8, Rio de Janeiro. Anais. Rio de Janeiro, 1996. p.561-567.

VIEIRA, R. Um olhar sobre a paisagem e o lugar como expressão do comportamento frente ao risco de deslizamento. 2004. $197 \mathrm{f}$. Tese (Doutorado) - Departamento de Geociências, Universidade Federal de Santa Catarina.

\title{
CONTRIBUIÇÃO DE AUTORIA
}

\section{NOTAS DE AUTOR}

Mario Tachini - Concepção. Coleta de dados, Análise de dados, Elaboração do manuscrito, revisão e aprovação da versão final do trabalho.

Dirceu L. Severo - Concepção. Coleta de dados, Análise de dados, Elaboração do manuscrito, revisão e aprovação da versão final do trabalho

Hélio dos Santos Silva - Concepção. Coleta de dados, Análise de dados, Elaboração do manuscrito, revisão e aprovação da versão final do trabalho

\section{FINANCIAMENTO}

Não se aplica

\section{CONSENTIMENTO DE USO DE IMAGEM}

Não se aplica

\author{
APROVAÇÃO DE COMITÊ DE ÉTICA EM PESQUISA \\ Não se aplica
}

CONFLITO DE INTERESSES

Não se aplica

\section{LICENÇA DE USO}

Este artigo está licenciado sob a Licença Creative Commons CC-BY. Com essa licença você pode compartilhar, adaptar, criar para qualquer fim, desde que atribua a autoria da obra. 
TACHINI, SEVERO, SILVA

HISTÓRICO

Recebido em: 13-09-2018

Aprovado em: 23-02-2021 